\title{
Innovation and Skills Workers of Mechanical Engineer to Design Smart Flush
}

\author{
W Omar Ali Saifuddin bin Wan Ismail ${ }^{1 *}$, Noraini binti Hamzah², Khalid bin Jusoh'
}

${ }^{1}$ Faculty of Innovative Design and Technology, Universiti Sultan Zainal Abidin

${ }^{2}$ Faculty of Engineering and Built Environment, National University of Malaysia

*Corresponding author E-mail: ainhamzah@ukm.edu.my

\begin{abstract}
Smart Flush is an innovative product in mechanical engineering. All the skilled workers need to improve the quality of product that would be manufacture. The three objectives of this study are as follows: (i) to design automatic water level control based on electrical conductivity of the water; (ii) to improve the supply of water into the water tank as well as avoiding any accessing water; and (iii) to provide easy installation and maintenance. $5 \mathrm{~W}+1 \mathrm{H}$ concept are used to solve the problem. The existing water level for toilet flushing system employs mechanical method, which is commonly expose to mechanical failure. This research introduces the notion of water level controlling within the context of electrical conductivity of the water. System design integrates the electrical and electronic based water level sensing and couple with solenoids shut off valve in a wired environment. The system equipment is lower power consumption, equipment only work when the water level changes, usually is in a waiting state. Smart Flush approach would help in reducing water overflow and low water pressure in the piping system. Maintaining water level inside the toilet pump system is an essential aspect in order to avoid waste of water due to overflow.
\end{abstract}

Keywords: Smart Flush, Solenoid Valve, Innovation, Skills Worker, Mechanical Engineer

\section{Introduction}

Today, various type and designs toilets have been produce and are still in use [1]. However, problems involving damage to equipment in the former involves floats, flushing tank valve balls and others have yet to be solve. This will also have a negative impact, such as the occurrence of wastage of water due to leakage, water overflow, illness problems and discomfort to the users of the toilet [2]. Elements of skills also reacted to change your career and life [3] expected to require technical skills as a basis of these generic skills that will allow creative problem solving [4]. The three objectives of this study are as follows: (i) to design automatic water level control based on electrical conductivity of the water: (ii) to improve the supply of water into the water tank as well as avoiding any accessing water: and (iii) to provide easy installation and maintenance.

In this study, researchers have used the concept of $5 \mathrm{~W}+1 \mathrm{H}$ to solve the problem. Among the questions raised are as follows: (i) what: high toilet pump damage. High means the total number of damage received in excess of the standards set. The standard is something received (recognized) and used as a basis for measuring such as weight, volume, value of money, quality standards and many others. While toilet pumps are water retention to keep the water at a certain level and then let through certain pressure flushing pipe to clean the toilet bowl and damages are failure on the system pump toilet that caused it cannot function properly; (ii) who: involving residential college campus in Gong Badak; (iii) where: In the toilet residential college campus in Gong Badak; (iv) when: while users are using the toilet; (v) why: adjustment system affected, less material, quality and ball valve lever pull the perishable and flushing systems are not effective. A leak in the unit floats also will affect the adjustment system. Water overflow, connecting chains affected will overwhelm the lever is pulled and a ball valve rubber hardens and tear cause incoming water flow cannot be controlled; and (vi) how: system toilets pumps existing are found to be effective and less quality materials used.

\section{Materials and Methods}

Basically, smart flush is an electronic circuit which written based on the detection of water levels, which give a text reminder via the LED lights goes on. This innovation is also used as an automatic water entry control which when the water level in the tank is less and the LED lights will light up when the water level is full according to the adjustments that can be set. Three proposal ideas broke out alternatives as shown: (i) adopts the solenoid valves for 
flushing process; (ii) use a push button switch; and (iii) using an electric current as a liaison. Solenoid valves is a valve that is powered by electricity, good AC or DC, have coil/spiral mobilizers, which works to move the piston at the Solenoid Valve [5].

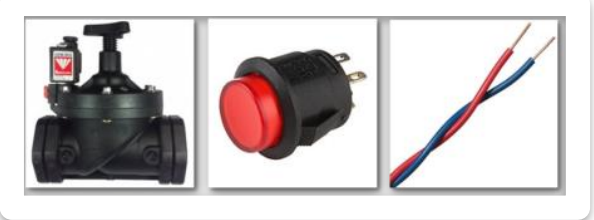

Fig. 1: Solenoid Valve, Push Button and Connecting Wire

An improvement action plan occurred with adding solenoid valves for flushing process, the use of the push button switch, use electric current liaison and less user friendly, and reduce damage to the flushing system [6]. As the proposed solution we are use of solenoid valve for flushing process, the wire used as liaison for connecting equipment to the system and push button switch is used to provide a signal to the solenoid valves to off/on for flushing process [7].

The solenoid valves is a system that is operate with an electric current in AC and DC valves via solenoid valves. Solenoid valves is the element of control is often use in fluid systems. As in pneumatic systems, hydraulic systems or at a machine control system enables the control elements automatically $[8,9]$. For example, of pneumatic solenoid valve system, on duty to control the airway pressure actuator pneumatic head (cylinder) or at a water filling valves, solenoid valves allows turn-down the water valve as arranger, so they don't get an empty tendon.

Between the parts of the Solenoid Valves are as follows: (i) A side Input; (ii) B - diaphragm; (iii) C - pressure chamber; (iv) D pressure relief passage; (v) E - Solenoid Valves; and (vi) F - output side, as shown in the diagram below [10].

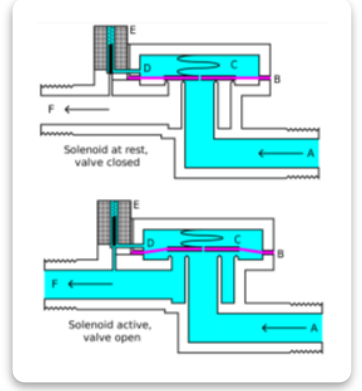

Fig. 2: Working Principle of Solenoid Valves

The solenoid valves will work when the loop gets tensile electric current corresponding to tensile work. Most of the work tensile is $100 /$ solenoid valves and valve while working at 200VAC tensile is DC $12 / 24$ VDC). A pin will be attracted because the magnetic style produced from the solenoid ring. While the pin is pulled up, then the fluid will flow from column $\mathrm{C}$ leading to D quickly constructed such that the pressure in the $\mathrm{C}$ down and incoming fluid pressure diaphragm lifting. The main cover open and fluid flow directly from section A to $\mathrm{F}[11]$.

Product development process in detail are displayed. The process of product development are involved all the step given. (i) identify problems that arise from damage to toilet pumps; (ii) list the characteristics needed to solve the problem; (iii) plan your needs equipment and expertise; (iv) create products (Smart Flush); (v) pilot test one; (vi) action correction; (vii) pilot test two; (viii) the standardization; (ix) monitoring; and (x) Standard Operating Procedures (SOP).

To produce the product innovation Smart Flush, researchers working through several steps as shown. Here are the sketches of creation are beginning Smart Flush system sketch and sketch the circuit schematic.
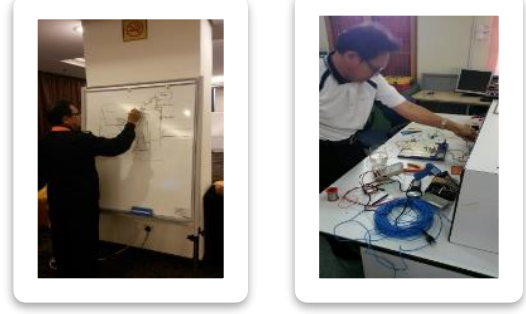

Fig. 3: Smart Flush System Sketch
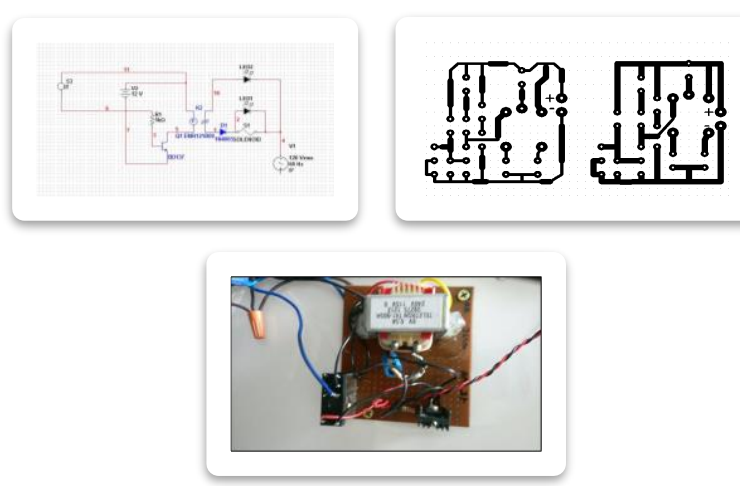

Fig. 4: Sketch and the Circuit Schematic

The next work step is implementation of this product development idea sketch and at this stage, detection tests conducted on LED components. The diagram shows, the LED does not go on when not able to detect the water level while the LED lights up when able to detect the water level.

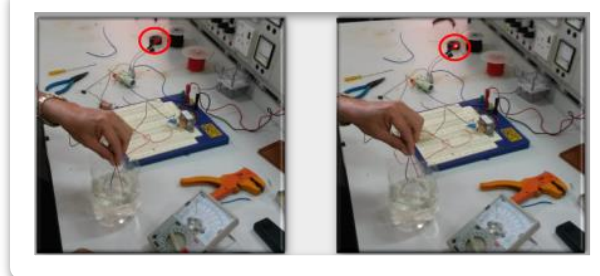

Fig. 5: LED Lights Up While Detect the Water Level

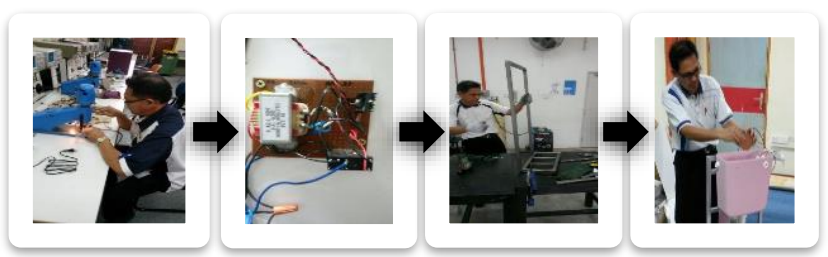

Fig. 6: Project Development Works

First, the punch holes in PCB process is carried out. Followed by the installation of electronic components on the $\mathrm{PCB}$, then built the prototype framework and the next step at this stage is the installation of electronic circuits on the prototype. During the implementation of a pilot test 2 was drawn, the prototype sketches 
made illustration sketch involved, frame and tank prototype adjuster and sketch full prototype. Researchers also attach the prototype drawings to indicate the products and projects with more clear to consumers.

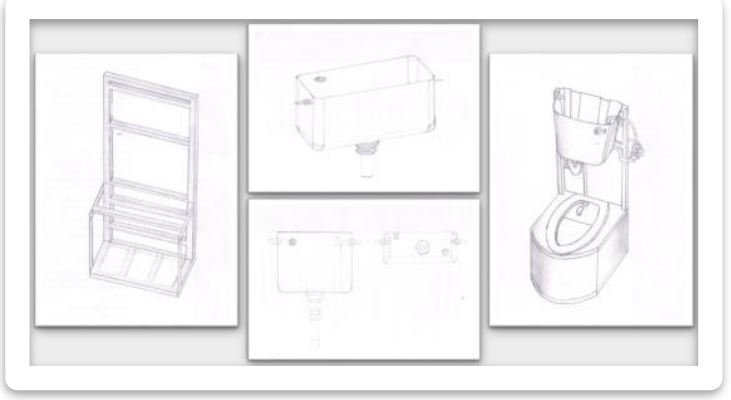

Fig. 7: The Prototype Sketches

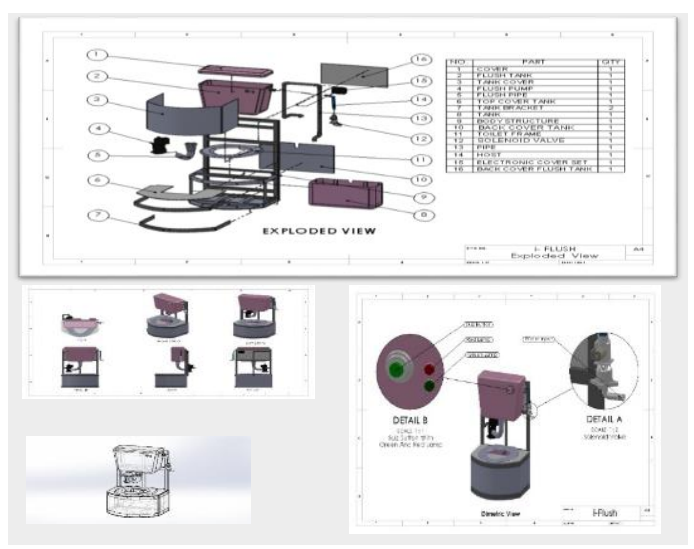

Fig. 8: Prototype Drawings

Based on the diagram above, each section have been label completely by researchers and the equipment details also shown to facilitate users. The information provided is clear and easy to understand as well as neatness. The main installation are as shown in the illustration below.

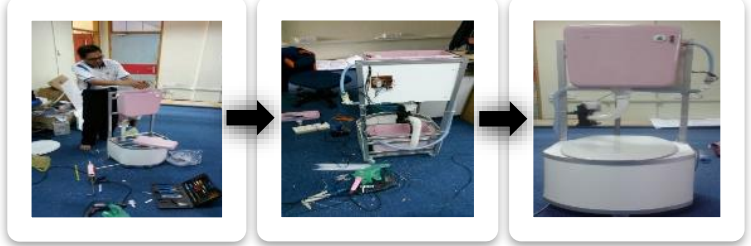

Fig. 9: Prototype Installation Works

\section{Results and Discussion}

Each innovation against a product or service with its own uniqueness that can be depicted. Similarly, Smart Flush features 5 unique, including: (i) never in any other organization by; (ii) the system can be applied to the water storage tank replace ball system; (iii) electric energy consumption is low; (iv) able to operate and survive in the longer period; and (v) the process of a simple and easy maintenance. Smart Flush are practical and low cost over the long run and fair, accurate, efficient, easy installation and maintenance. It also has a novelty such as applying concept and inventiveness of electrical conductivity activated, easy adjustable water level and low maintenance cost. If seen from the point of commercialization potentials flush targets all $R \& R$, houses, hotels, home stay and public hotel to be replaced with this innovative project.
This innovation made a positive impact to a lot of parties. Among them are the impact to the customer, organization, government, stakeholders and the environment. A clear impact to customers can be seen through the graph provided. The initial target setting performed by researchers are $85 \%$ decline in the number of damage. Finally achievements exceeds the target where the amount of zero damage.

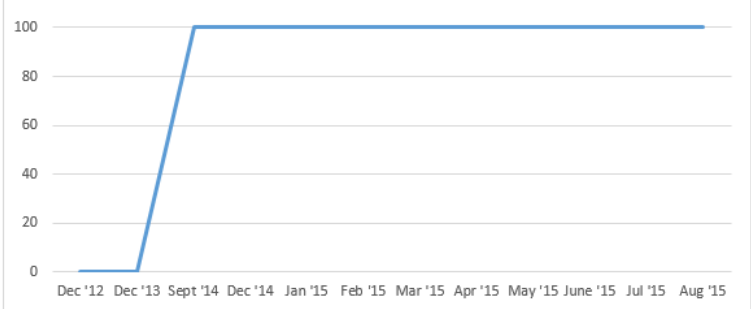

Fig. 10: Group Target Achieved

Based on the graphs recorded, before the project carried out between December 2012 and December 2013, it does not apply any reduction in the number of damage recorded. Once the project started to run and at the level of the pilot test, the amount of the reduction occurred 1 drastically in September 2014. Then, the pilot test were carried out on December 2014, followed by a wide monitoring process from January 2015 until March 2015. The process of standardization directly undertaken by researchers between March 2015 to mid May 2015. A continuous monitoring process taking place until August 2015.

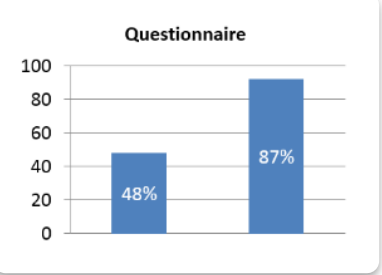

Fig. 11: The Level of Customer Satisfaction

Through the distributed questionnaire, the information obtained are as follows: before the innovation, only $48 \%$ of clients satisfied with the commonly use type of toilet. After the innovations were done on the toilet, $87 \%$ of the customers are satisfied.

Table 1: Questionnaire Feedback

\begin{tabular}{|c|l|c|c|}
\hline No. & \multicolumn{1}{|c|}{ Questions Item } & Agree & Disagree \\
\hline 1. & $\begin{array}{l}\text { help improve pump toilet facilities for the } \\
\text { user rankings }\end{array}$ & $82 \%$ & $18 \%$ \\
\hline 2. & $\begin{array}{l}\text { products produced much help in reducing the } \\
\text { damage of the pump the toilet }\end{array}$ & $87 \%$ & $13 \%$ \\
\hline 3. & $\begin{array}{l}\text { the product was able to maximize the use of } \\
\text { the pump toilets available }\end{array}$ & $82 \%$ & $18 \%$ \\
\hline 4. & $\begin{array}{l}\text { the use of the product can save the mainte- } \\
\text { nance cost of the pump the toilet }\end{array}$ & $90 \%$ & $10 \%$ \\
\hline 5. & $\begin{array}{l}\text { use of the product can solve the problem of } \\
\text { high toilet pump damage }\end{array}$ & $90 \%$ & $10 \%$ \\
\hline 6. & the product produced is user friendly & $85 \%$ & $10 \%$ \\
\hline 7. & $\begin{array}{l}\text { the product can function properly and } \\
\text { running with smooth }\end{array}$ & & $15 \%$ \\
\hline
\end{tabular}


Among the questions posed were: (i) $82 \%$ agree help improve pump toilet facilities for the user rankings; (ii) $87 \%$ agree products produced much help in reducing the damage of the pump the toilet; (iii) $82 \%$ agree, the product was able to maximize the use of the pump toilets available; (iv) - $90 \%$ agree the use of the product can save the maintenance cost of the pump the toilet; (v) $90 \%$ agree use of the product can solve the problem of high toilet pump damage; (vi) $85 \%$ agree the product produced is user friendly; and (vii) $90 \%$ agree the product can function properly and running with smooth. Results of the findings was obtained by engaging staff and students of the university.

The positive impact of organizations can be seen with the occurrence of significant cost savings in monthly or yearly maintenance. Total savings confirmed by Assistant Accountant, Department of Management Development. Something to be proud of is the result of the savings made, a sum of money that has been provided for maintenance before, can now be distributed to other responsibility centers according to their needs.

Implementation of the Smart Flush system also left an impact to the government and a stakeholder. It can reduce the maintenance and cost of which at once be able to identify and remove components and costs does not contribute to the value of the service, system and project, which is in accordance with the recommendations of the government to achieve value for money. Apart from the waste of government money could be reduced thus foster the competitive spirit, creativity and innovativeness.

Smart Flush also left an impact to the environment through the increase in the level of cleanliness of toilets and it is able to solve the problem of water wastage in the toilet residential college. Moreover, Smart Flush using solenoid valves obtained from used items are one of the principle of recycling.
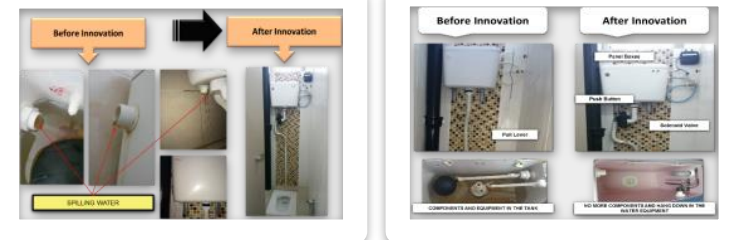

Fig. 12: Before and After Innovation

Summary of expenses incurred in producing the Smart Flush system is as per table below. At the beginning, this system installed on 24 units in the toilet at a residential college, then the cost of the Smart Flush system for 24 units as shown.

Table 2: The Cost of the Smart Flush System

\begin{tabular}{|c|l|c|c|}
\hline No. & \multicolumn{1}{|c|}{ Item } & Cost (RM) / unit & $\begin{array}{c}\text { Cost (RM) / 24 } \\
\text { units }\end{array}$ \\
\hline 1 & Relay (12 volt) & 2.50 & 60.00 \\
\hline 2 & Transistor (BD137) & 0.40 & 9.60 \\
\hline 3 & Resistor (1 kilo ohm) & 0.10 & 2.40 \\
\hline 4 & LED (Red) & 0.40 & 9.60 \\
\hline 5 & LED (Green) & 0.40 & 9.60 \\
\hline 6 & Solenaid Valve (2 unit) & 28.00 & 672.00 \\
\hline 7 & Tranformer (9v0.05A) & 9.00 & 216.00 \\
\hline 8 & PCB & 1.20 & 28.80 \\
\hline
\end{tabular}

The cost is shown if the use of the toilet pump continuously for 12 hours. The use of completely electricity only happens when the process of flushing to occur. Project monitoring is carried out directly by holding control contingency plans and maintenance products and Smart Flush system. There is a risk that needs to be faced when using this system, but the action and preventive measures have been taken to ensure that the Smart Flush depth would function in any way whatsoever. In the event of the occurrence if the electricity would cut off, it is not a big problem because the battery support as the power supply is also available. Costs for each LED to lights up does not work or only require a small amount of money to be replaced again. Monthly and annual maintenance costs reduced in total depth.

\section{Conclusions}

Through research, there are many unique products that have been identified. Among them are: (i) adjustment work easily adjusted; (ii) save maintenance costs; (iii) has a filter to prevent the entry of impurities; (iv) ensure the overflow problem; (v) facilitating monitoring during maintenance work; (vi) ensure the safety of the user; (vii) is new ideas and innovation; (viii) optimize the use of existing facilities; and (ix) the system can be mounted directly onto existing toilet pump. The existence of Smart Flush system also could improve the quality of services at once for pumps provided toilets, especially in areas with many visitors, in public places or in the exclusive toilet. Toilet hygiene is also more secure compared to the types of toilets being used now. Moreover, it saves the costs of toilet pump system and the amount of maintenance to address the issue of overhaul of equipment damage in the box of the pump the toilet can be solve.

\section{Acknowledgements}

The author wish to thank the other members of Universiti Sultan Zainal Abidin for their help of this work. Special thanks to Dr. Noraini Hamzah from The National University of Malaysia as a supervisor provided many useful discussion. The research was supported by a Ministry of Higher Education (MoHE) by SLAB 
scheme. The data presented, the statements made, and the views expressed are solely the responsibility of the author.

\section{References}

[1] S. K. Singh, Anshika Bisht (2015). Environmental Management In Mass Gatherings. International Journal Of Engineering Sciences. Bisht, 5(1): January-March, 2015.

[2] 2. Md Moniruzzaman (2015). A Study on Dealer's Preference towards Water Pumps with Special Reference to Beacon Pump in Chennai City. Global Journal of Management and Business Research: E Marketing - Volume 15 Issue 1 Version 1.0 Year 2015.

[3] Hosseini, A.S. (2014). Survey the Influence of the Creativity Teaching Model on Teachers' Knowledge, Attitude, and Teaching Skills. International Journal of Sociology of Education, 3(2), 106-117. doi: 10.4471/rise.2014.08.

[4] 4. Tarum K., Walz E., Korte R., Valeri M.s., Hahn L.D., Sunderman J.A., Bruce P.J. (2013). Knowledge, Skills, and Attitudes Acquired through Engineering Student Experiences Abroad.

[5] 5. T. Baranidharan, A.Chinnadurai2, R.M.Gowri3, J Karthikeyan4 (2015). Automated Water Distribution System Using PLC And SCADA. International Journal of Electrical and Electronics Engineers - Volume 07, Issue 01, Jan- June 2015.

[6] 6. Jin Yunxhen, DENG Ruoyu, JIN Yingzi, HU Xudong (2013). Research of the Response Characteristics of Solenoid Valve of the Air-jet Loom by Simulation. Journal of Thermal Science Vol. 22, No. 6 (2013).

[7] 7. Xiao Ying1, Zhu Bing1, Liu Yong2, and Peng Xuange1,2 (2009), The Automatic Monitoring Device of Ground water Level Based on Embedded Systems, Proceedings of the 2009 International Symposium on Information Processing (ISIP'09) Huangshan, P. R. China, pp. 241-244

[8] 8. Dipak P. Patil, Pooja K. Nagare, Rashmi V. Nerkar, Snehal S.Dholi (2015). PLC Controller for Hydraulic operated unscrewing machine: Issues and Proposed System - Volume 4, Issue 4 April 2015.

[9] P.Balashanmugam, K.Balasubramaniyan, G.Balasubramaniyan3, S.Vinoth (2013). Fabrication Of High Speed Indication And Automatic Pneumatic Braking System. International Journal of Engineering Trends and Technology (IJETT) - Volume 5 number 1 - Nov 2013.

[10] 10. D.Baladhandabany, S.Gowtham, T.Kowsikkumar, P.Gomathi (2015). Plc Based Automatic Liquid Filling System Vol.4 Issue. March- 2015, pg. 684-692.

[11] 11. Key-Sun Kim. Structure and Vibration Analysis of Solenoid Pump for Two-way Hydraulic Control (2013). International Journal of Control and Automation - Vol.6, No.6 (2013), pp.4150 